\title{
Hypercalcemia in T-Cell/Histiocyte-Rich Large B-Cell Lymphoma: An Unusual Presentation of a Rare Disease and Literature Review
}

\author{
Gabriella A. Conte ${ }^{\mathrm{a}, \mathrm{f}}$, Jonathan S. Harmon ${ }^{\mathrm{b}}$, Marjolein L. Le ${ }^{\mathrm{c}}$, Xiu Sun ${ }^{\mathrm{d}}$, Jake W. Schulere, \\ Michael J. Levitta ${ }^{\mathrm{a}}$, Angelo A. Chinnicia, Mohammad A. Hossain ${ }^{\mathrm{a}}$
}

\begin{abstract}
T-cell/histiocyte-rich large B-cell lymphoma (THRLBCL) is an extremely rare morphologic subtype of diffuse large B-cell lymphoma (DLBCL), accounting for only $1-3 \%$ of total cases. It is considered an aggressive lymphoma with a poor prognosis. Hypercalcemia has been described as an uncommon presenting symptom of patients with DLBCL in several case reports. Here, we report an unusual case of severe hypercalcemia in a patient who was ultimately diagnosed with T-cell/histiocyte-rich B-cell lymphoma. A 69-year-old male patient presented to our hospital with nausea, vomiting, weakness and unintentional weight loss. His initial blood tests showed a serum calcium level of $16.1 \mathrm{mg} / \mathrm{dL}$ and serum creatinine level of $3.25 \mathrm{mg} / \mathrm{dL}$. He had high intact parathyroid hormone (PTH, $6.8 \mathrm{pg} / \mathrm{mL})$, mildly elevated 25-hydroxyvitamin D and serum PTH-related peptide (PTHrP). To exclude malignancy, computed tomography (CT) scans of the chest, abdomen and pelvis were performed which were unremarkable. A bone marrow biopsy was performed to detect any hidden hematologic malignancy which showed large mononuclear cells with prominent nucleoli and occasional Reed-Sternberg cells, consistent with the diagnosis of THRLBCL. Subsequent positron emission tomography demonstrated diffuse fluorodeoxyglucose (FDG) uptake. This case reports a unique presentation of a rare subtype of non-Hodgkin's lymphoma. We highlight the importance of pursuing a thorough workup for causes of hypercalcemia as well as understanding the underlying mechanisms of severe hypercalcemia in malignancy.
\end{abstract}

Keywords: Hypercalcemia; T-cell/histiocyte-rich large B-cell lymphoma; Diffuse large B-cell lymphoma; Malignancy

Manuscript submitted November 18, 2019, accepted December 2, 2019

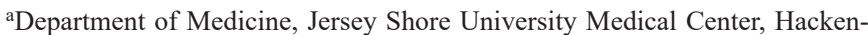
sack Meridian Health, NJ, USA

bDepartment of Medicine, Jefferson Health New Jersey, Jefferson University Hospital, Stratford, NJ, USA

'Department of Medicine, Easton Hospital, Easton, PA, USA

${ }^{\mathrm{d} D e p a r t m e n t}$ of Pathology, Jersey Shore University Medical Center, Hackensack Meridian Health, Neptune, NJ, USA

eSaint George's University School of Medicine, Grenada, West Indies

${ }^{f}$ Corresponding Author: Gabriella A. Conte, Department of Medicine, Jersey

Shore University Medical Center, Hackensack Meridian Health, Neptune, NJ

07753, USA. Email: gabriella.conte@hackensackmeridian.org

doi: https://doi.org/10.14740/wjon1246

\section{Introduction}

Diffuse large B-cell lymphoma (DLBCL) is the most common histologic subtype of non-Hodgkin's lymphoma (NHL), accounting for about $25 \%$ of all adult NHLs worldwide [1]. DLBCL is a heterogeneous group of tumors including large transformed B cells with prominent nucleoli and basophilic cytoplasm, a diffuse growth pattern and 30-90\% Ki67 positive cells [2]. DLBCL tumor cells express pan B cell antigens (cluster of differentiation (CD)19, CD20, CD22, CD79a, PAX5), but there is no single diagnostic cytogenetic change [2]. T-cell/ histiocyte-rich large B-cell lymphoma (THRLBCL) is an extremely rare morphologic subtype of DLBCL, accounting for only $1-3 \%$ of total cases [3-6]. The World Health Organization (WHO) defines THRLBCL as the presence of less than $10 \%$ of large malignant CD20-expressing B cells scattered in a background of predominant reactive $\mathrm{T}$ cells and histiocytes [1]. At presentation THRLBCL is often seen in middle-aged men with an advanced stage (III or IV) frequently involving the spleen, liver and bone marrow [7]. Given this, THRLBCL is considered an aggressive lymphoma with a poor prognosis. Hypercalcemia has been reported in up to $15 \%$ of NHL patients during their clinical course but is uncommon at diagnosis [8]. Hypercalcemia has been described as a rare presenting symptom of patients with DLBCL in several case reports [911]. Presently, there is no published case report in the literature of THRLBCL presenting as severe hypercalcemia. In this paper, we describe the first case.

\section{Case Report}

A 69-year-old male with a history of hypothyroidism and hypertension presented to the Emergency Department of our hospital with complaints of nausea, vomiting, and generalized weakness with left-sided discomfort for the last 2 weeks. The patient also reported unintentional 80-pound weight loss over the last 1 year. He denied fevers, chills or night sweats. Upon initial physical examination the patient was cachectic with dry mucous membranes. The remainder of the exam was within normal limits. His vital signs were as follows: blood pressure: 136/72 mm Hg; heart rate: 90 beats per minute; respiratory rate: $18 / \mathrm{min}$; body temperature: $36.6{ }^{\circ} \mathrm{C}$; oxygen saturation: 
Table 1. Summary of Laboratory Results

\begin{tabular}{|c|c|c|}
\hline & Result & $\begin{array}{l}\text { Reference } \\
\text { range }\end{array}$ \\
\hline \multicolumn{3}{|l|}{ Complete metabolic panel } \\
\hline Sodium (mmol/L) & 138 & $136-145$ \\
\hline Potassium (mmol/L) & 4.1 & $3.5-5.2$ \\
\hline Chloride (mmol/L) & 96 & $96-110$ \\
\hline Bicarbonate (mmol/L) & 29 & $24-31$ \\
\hline Calcium (mg/dL) & 16.1 & $8.5-10.5$ \\
\hline Magnesium (mg/dL) & 1.9 & $1.3-2.5$ \\
\hline Phosphorous (mg/dL) & 5.8 & $2.5-4.6$ \\
\hline BUN (mg/dL) & 67 & $5.0-25$ \\
\hline Creatinine (mg/dL) & 3.25 & $0.61-1.24$ \\
\hline eGFR (mL/min) & 19 & $>60$ \\
\hline Intact parathyroid hormone (pg/mL) & 6.8 & $15-65$ \\
\hline PTH-related peptide(pmol/L) & 3.7 & $0.0-2.3$ \\
\hline 25-hydroxyvitamin D (pg/mL) & 168 & $19.9-79.3$ \\
\hline ß2-microglobulin (mg/L) & 9.8 & $1.1-2.4$ \\
\hline \multicolumn{3}{|l|}{ Complete blood count } \\
\hline WBC $\left(\times 10^{3} / \mu \mathrm{L}\right)$ & 4.3 & $4.5-11.0$ \\
\hline Hemoglobin (g/dL) & 11.4 & $12.0-17.5$ \\
\hline Hematocrit (\%) & 34.0 & $36.0-53.0$ \\
\hline MCV (fL) & 84.0 & $80.0-100$ \\
\hline $\mathrm{MCH}(p g)$ & 28.1 & $25.0-35.0$ \\
\hline Platelet count $\left(\times 10^{3} / \mu \mathrm{L}\right)$ & 206 & $140-450$ \\
\hline \multicolumn{3}{|l|}{ Iron panel } \\
\hline Iron $(\mu \mathrm{g} / \mathrm{dL})$ & 78 & $45-180$ \\
\hline Iron binding $(\mu \mathrm{g} / \mathrm{dL})$ & 265 & $260-480$ \\
\hline Ferritin $(\mathrm{ng} / \mathrm{mL})$ & 681.5 & $24-336$ \\
\hline Transferrin $((\mathrm{mg} / \mathrm{dL}))$ & 189 & $215-365$ \\
\hline Transferrin \% saturation (\%) & 29.5 & $15-50$ \\
\hline
\end{tabular}

$98 \%$ at room air.

The results of a complete metabolic panel (Table 1) showed serum calcium level elevated at $16.1 \mathrm{mg} / \mathrm{dL}$. The patient was admitted to the intensive care unit for severe hypercalcemia, for which he received aggressive intravenous fluid resuscitation with $2 \mathrm{~L}$ normal saline followed by maintenance fluids at $150 \mathrm{~mL} / \mathrm{h}$ (with goal urine output $100 \mathrm{~mL} / \mathrm{h}$ ), as well as intravenous calcitonin for goal decrease in serum calcium of $2 \mathrm{mg} / \mathrm{dL} / 24 \mathrm{~h}$. Several hours after administration of calcitonin, serum calcium level decreased to $13.5 \mathrm{mg} / \mathrm{dL}$. In addition, serum blood urea nitrogen and creatinine were initially elevated at $67 \mathrm{mg} / \mathrm{dL}$ and $3.25 \mathrm{mg} / \mathrm{dL}$, respectively. Thyroid function test was normal. Furthermore, serum assay of intact parathyroid hormone (iPTH) was $6.8 \mathrm{pg} / \mathrm{mL}$ (range: 15 - $65 \mathrm{pg} / \mathrm{mL}$ ), serum 25-hydroxyvitamin D (25(OH)D) level was $168 \mathrm{pg} / \mathrm{mL}$ (range: 19.9 - $79.3 \mathrm{pg} / \mathrm{mL}$ ), and serum PTH-related peptide (PTHrP) was elevated at $3.7 \mathrm{pmol} / \mathrm{L}$ (range: 0.0 - $2.3 \mathrm{pmol} / \mathrm{L}$ )
(Table 1). A workup for anemia was simultaneously carried out (Table 1). Iron panel was consistent with anemia due to chronic disease. The peripheral blood smear was unremarkable. The level of $\beta 2$-microglobulin was elevated to $9.8 \mathrm{mg} / \mathrm{L}$ (range: $1.1-2.4 \mathrm{mg} / \mathrm{L}$ ). Due to the combination of severe hypercalcemia, renal failure and anemia, serum and urine electrophoreses were performed to rule out multiple myeloma. Both tests were negative. Computed tomography (CT) chest/abdomen/pelvis and CT head were unremarkable. Skeletal survey was within normal limits. A bone marrow biopsy at the left posterior superior iliac spine was then performed to exclude any hematologic malignancy. The bone marrow smear revealed large mononuclear cells with prominent nucleoli and occasional Reed-Sternberg cells, consistent with THRLBCL (Fig. 1). The atypical cells exhibited the following immunophenotype: cluster of differentiation (CD) $30+, \mathrm{CD} 20+, \mathrm{PAX} 5+$, organic cation transporter 2 (Oct2)+, BOB1+, CD79a+, BCL6+, BCL2+, C$\mathrm{MYC}+, \mathrm{MIB} 1+$, and MUM1+. CD3 marks associated T-cell infiltrate. Special staining with CD71, CD61 and myeloperoxidase (MPO) was utilized. Flow cytometry and cytogenetics were unremarkable. This pathology was reviewed in consultation with the pathologist from the National Institute of Health, who confirmed the morphological and immunohistochemical characterization of THRLBCL.

Throughout his hospital stay the patient remained on intravenous maintenance normal saline at $150 \mathrm{~mL} / \mathrm{h}$, and his creatinine improved to 1.68 prior to discharge. In addition, patient received intravenous calcitonin, one dose of intravenous pamidronate and furosemide, and zoledronic acid for symptomatic hypercalcemia which significantly improved his calcium to 10.9 at its lowest. The patient was discharged in a stable condition with close follow-up. A following outpatient positron emission tomography/computed tomography (PET/CT) scan showed extensive skeletal metastatic disease with fluorodeoxyglucose (FDG) uptake involving all bones, 5 -cm mediastinal mass and diffuse splenic disease with $3.98-\mathrm{cm}$ mass, an atypical presentation of lymphoma (Fig. 2). The patient's international prognostic index (IPI) was 4 which indicated high risk for shorter overall survival, specifically $26 \%$ chance 5 -year survival according to the International Peripheral T-cell Lymphoma Project [12]. The patient consistently followed up as an outpatient with medical oncology and completed four cycles of hyperfractionated cyclophosphamide, vincristine, doxorubicin and dexamethasone (hyper-CVAD) chemotherapy without complications. After 8 months of initial presentation, repeat PET/CT showed complete remission of his lymphoma with improvement of labs. The patient remained in complete remission for over 1 year since the end of treatment. At his most recent office visit, patient was asymptomatic with positive weight gain and normal appetite.

\section{Discussion}

This case highlights the importance of pursuing a thorough workup for rare underlying causes of hypercalcemia, especially in patients who show elevated PTHrP. Hypercalcemia is commonly seen in $20-30 \%$ of cancer cases, occurring in both solid and hematologic malignancies [13]. The most common 

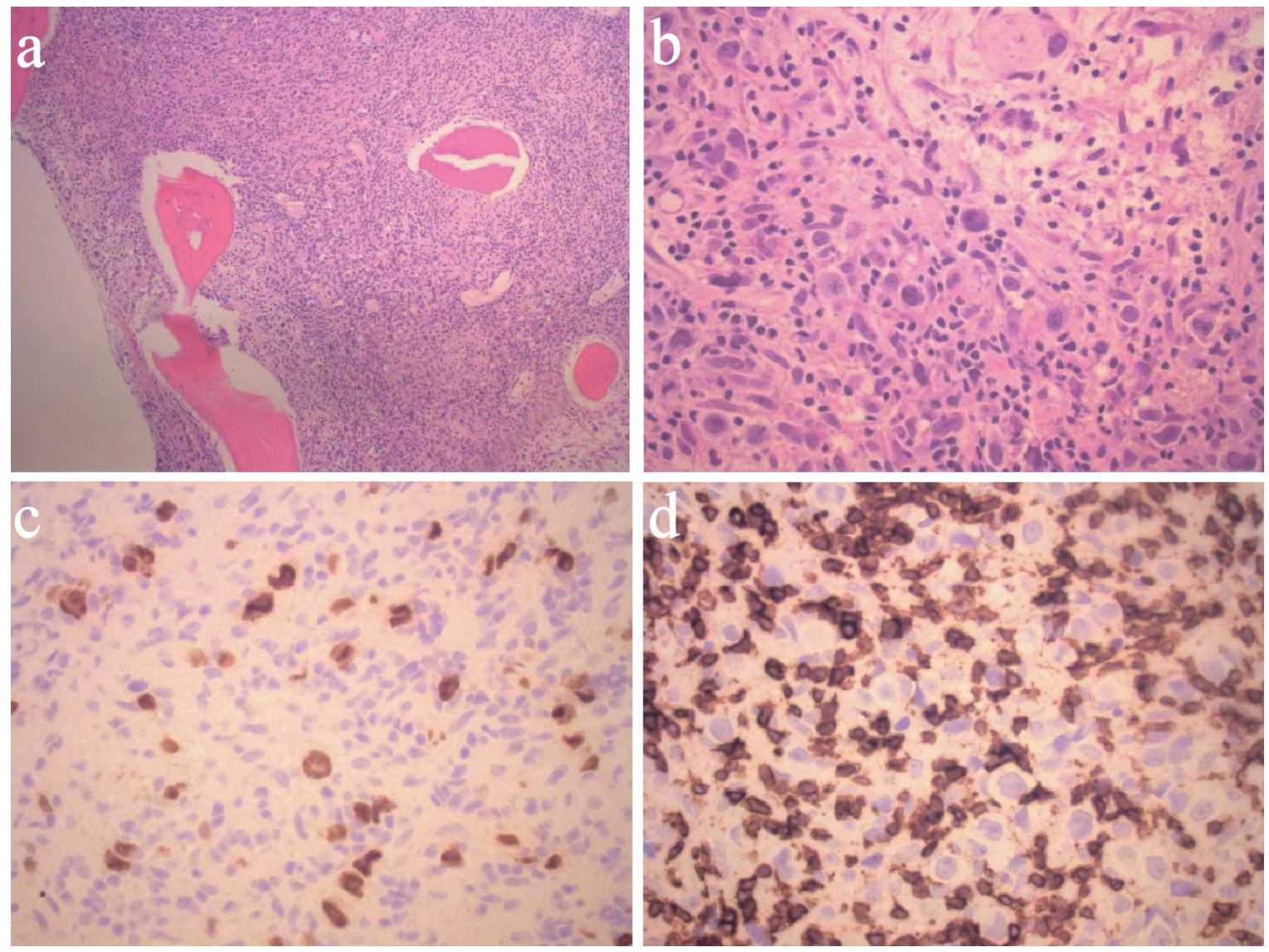

Figure 1. Bone marrow smears demonstrating T-cell/histiocyte rich large B-cell lymphoma. (a) Low-power view. (b) High-power view. (c) PAX8 immunostain. (d) CD3 immunostain. CD: cluster of differentiation. BUN: blood urea nitrogen; eGFR: estimated glomerular filtration rate; WBC: white blood cell; MCV: mean corpuscular volume; $\mathrm{MCH}$ : mean corpuscular hemoglobin.

cancers in the USA that are associated with hypercalcemia are multiple myeloma, breast, renal and lung cancers [14]. Malignancy is usually clinically evident by the time it causes hypercalcemia. Symptoms can include lethargy, weakness dehydration, nausea, vomiting and constipation. Only $15 \%$ of NHL patients will develop hypercalcemia during their overall clinical course [8]. But rarely does hypercalcemia manifest at the time of diagnosis. Hypercalcemia of malignancy is often associated with poor prognosis, and therefore, it is important to understand the mechanisms behind hypercalcemia associated with cancer.

Three major mechanisms by which hypercalcemia of malignancy can occur have been described in the literature: tumor secretion of PTHrP, osteolytic metastases with local release of cytokines and osteoclast activating factors, and tumor production of calcitriol $(1,25$-dihydroxyvitamin D) $[13,15,16]$. The most common mechanism of hypercalcemia (accounting up to $80 \%$ ) in patients with NHL and non-metastatic tumors is secretion of PTHrP, known as humoral hypercalcemia of malignancy (HHM) [17-19]. Malignant tissues such as squamouscell carcinomas (lung, head and neck), breast cancer, chronic myeloid leukemia and NHL produce excess PTHrP, resulting in HHM. PTHrP has close homology with PTH and binds to the same PTH-1 receptors, thus activating similar pathways.
PTHrP circulates throughout the body and increases distal tubular calcium reabsorption and bone resorption, resulting in large flux of calcium storage release into the circulation [19, 20]. Conversely, osteolytic metastases account for merely $20 \%$ of cases of hypercalcemia with malignancy [21]. In solid tumors that are metastatic to bone, tumor cells produce factors that stimulate osteoclast production. This in turn induces local osteolysis, increased skeletal resorption and hypercalcemia. Another common mechanism by which hypercalcemia of malignancy can occur is increased production of calcitriol by certain lymphomas. Active secretion stimulates both osteoclastic bone resorption and intestinal calcium absorption, leading to hypercalcemia [13].

Upon evaluating the cause of severe unexplained hypercalcemia, the first step is to measure the iPTH value to screen for HHM. A low serum iPTH suggests the possibility of malignancy and warrants measurement of PTHrP and vitamin D [22]. In contrast, an elevated PTH indicates primary hyperparathyroidism. Additional laboratory data such as serum protein electrophoresis (SPEP), urine protein electrophoresis (UPEP) and thyrotropin (TSH) can aid in identifying other possible sources for hypercalcemia. PTHrP elevation is often seen in HHM but can also be due to other benign conditions such as systemic lupus erythematosus [23]. Therefore, it is important 


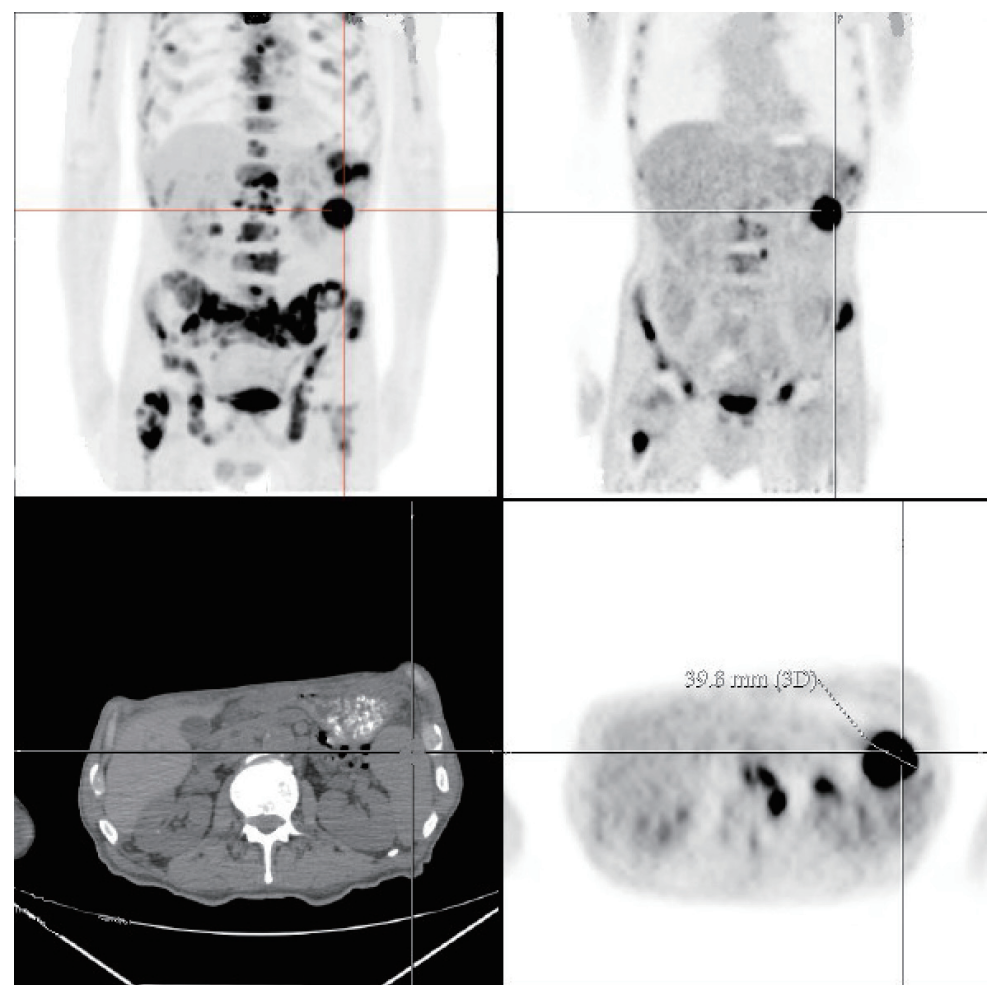

Figure 2. Torso positron emission tomography/computed tomography scan demonstrates diffuse fluorodeoxyglucose (FDG) uptake and a 3.98-cm splenic mass.

to pay careful attention to laboratory interpretation in patients who present with severe hypercalcemia of unclear etiology.

There are several case reports that describe lymphomas presenting as severe, unexplained hypercalcemia [9-11, 24, 25]. Hong et al reported a case of DLBCL in a 72-year-old male who presented with worsening confusion and dehydration and who, like our case, was found to have severe hypercalcemia along with high plasma concentration of PTHrP. Subsequent imaging revealed a large hepatosplenic mass. Pathology confirmed diagnosis of DLBCL [10]. Tumor cell production of PTHrP likely explained the pathogenesis of hypercalcemia. However, our case is unique as this patient presented with severe hypercalcemia as the initial manifestation of THRLBCL, an extremely rare subtype of DLBCL. Ha et al also described a 68-year-old male who presented with lethargy, weight loss, severe hypercalcemia and elevated PTHrP. PET/CT imaging likewise revealed diffuse FDG uptake in the bones and spleen. Up until now, however, there are no published cases in the literature that describe hypercalcemia as a rare manifestation of THRLBCL [9].

Given the rarity, aggression and acuity of THRLBCL as a distinct clinicopathologic entity, successful treatment outcomes have not yet been well reported as uncertainty remains regarding the best therapeutic approach. Achten et al reports the IPI as a significant correlate to response to treatment and survival based on multivariate analysis. In this study on 40 THRLBCL patients, the IPI was $\geq 2$ in $77 \%$ of the patients [26]. Despite treatment with combination chemotherapy, complete remission was attained in only $40 \%$ of patients with an overall survival rate of $50 \%$ at 3 years. Moreover, several retrospective studies that compared overall and event-free survival rates between DLBCL and THRLBCL patients treated with CHOP (cyclophosphamide, doxorubicin, vincristine, and prednisone) therapy showed that THRLBCL has a worse prognosis, thus requiring more aggressive therapy [26, 27]. Although THRLBCL confers a poor prognosis, our patient with an IPI score of 4 achieved complete remission by treatment with four cycles of hyper-CVAD. Nevertheless, insights into the pathogenesis of this disease should be explored further to achieve targeted therapies that can offer a more favorable treatment response.

\section{Conclusions}

In conclusion, we present a unique presentation of an extremely rare clinicopathologic entity. A literature search revealed no previously reported cases of THRLBCL manifesting as severe hypercalcemia. We thus suggest that THRLBCL should be included in the differential diagnosis and active workup in patients with severe unexplained hypercalcemia in appropriate clinical scenario, as this aggressive malignancy with poor prognosis requires prompt recognition and treatment.

\section{Acknowledgments}

The authors gratefully acknowledge the support of the Department of Pathology at Jersey Shore University Medical Center, 
Hackensack Meridian Health. We thank our patient who kindly gave his consent for this publication.

\section{Financial Disclosure}

This project was not supported by any grant or funding agency.

\section{Conflict of Interest}

The authors declare that there is no conflict of interest regarding the publication of this paper.

\section{Informed Consent}

The patient described in the case report had given informed consent for the case report to be published.

\section{Author Contributions}

GAC contributed in case selection, planning and drafting the manuscript. JSH contributed in discussion part and edition of the manuscript. MLL contributed in the case discussion part of the manuscript. XS contributed to the pathological slide review and discussion. JWS contributed to case planning and collecting radiographic images. MJL reviewed and finalized the manuscript. AAC contributed significantly in preparation of the manuscript and collecting radiographic images. $\mathrm{MAH}$ contributed significantly in manuscript revision, editing and final approval.

\section{References}

1. Swerdlow SH, Campo E, Pileri SA, Harris NL, Stein H, Siebert R, Advani R, et al. The 2016 revision of the World Health Organization classification of lymphoid neoplasms. Blood. 2016;127(20):2375-2390.

2. Said JW. Aggressive B-cell lymphomas: how many categories do we need? Mod Pathol. 2013;26(Suppl 1):S4256.

3. Gatter KC, Warnke RA. Diffuse large B-cell lymphoma. World Health Organization classification of tumors: pathology and genetics of tumours of haematopoietic and lymphoid tissues. 2001;3:171-174.

4. Pfreundschuh M, Trumper L, Kloess M, Schmits R, Feller AC, Rube C, Rudolph C, et al. Two-weekly or 3-weekly CHOP chemotherapy with or without etoposide for the treatment of elderly patients with aggressive lymphomas: results of the NHL-B2 trial of the DSHNHL. Blood. 2004;104(3):634-641.

5. Pfreundschuh M, Trumper L, Kloess M, Schmits R, Feller AC, Rudolph C, Reiser M, et al. Two-weekly or 3-weekly CHOP chemotherapy with or without etoposide for the treatment of young patients with good-prognosis (normal
LDH) aggressive lymphomas: results of the NHL-B1 trial of the DSHNHL. Blood. 2004;104(3):626-633.

6. Bouabdallah R, Mounier N, Guettier C, Molina T, Ribrag $\mathrm{V}$, Thieblemont C, Sonet A, et al. T-cell/histiocyte-rich large B-cell lymphomas and classical diffuse large B-cell lymphomas have similar outcome after chemotherapy: a matched-control analysis. J Clin Oncol. 2003;21(7):12711277.

7. Fan Z, Natkunam Y, Bair E, Tibshirani R, Warnke RA. Characterization of variant patterns of nodular lymphocyte predominant hodgkin lymphoma with immunohistologic and clinical correlation. Am J Surg Pathol. 2003;27(10):1346-1356.

8. Burt ME, Brennan MF. Incidence of hypercalcemia and malignant neoplasm. Arch Surg. 1980;115(6):704-707.

9. Ha JM, Kim E, Lee WJ, Hwang JW, Yune S, Ko YH, Choi JY, et al. Unusual manifestation of intravascular large B-cell lymphoma: severe hypercalcemia with parathyroid hormone-related protein. Cancer Res Treat. 2014;46(3):307-311.

10. Hong H, Hayashi T, Hagiwara K, Sugiyama H, Ando K, Kim S, Hino M. [Hypercalcemia associated with parathyroid hormone-related protein(PTHrP)in a patient with diffuse large- type B-cell lymphoma(DLBCL)]. Gan To Kagaku Ryoho. 2011;38(11):1881-1884.

11. Yoo JS, Kim J, Kwon HJ, Lim JS. Primary bone marrow B-cell lymphoma undetected by multiple imaging modalities that initially presented with hypercalcemia. Case Rep Endocrinol. 2018;2018:7676580.

12. Weisenburger DD, Savage KJ, Harris NL, Gascoyne RD, Jaffe ES, MacLennan KA, Rudiger T, et al. Peripheral Tcell lymphoma, not otherwise specified: a report of 340 cases from the International Peripheral T-cell Lymphoma Project. Blood. 2011;117(12):3402-3408.

13. Stewart AF. Clinical practice. Hypercalcemia associated with cancer. N Engl J Med. 2005;352(4):373-379.

14. Gastanaga VM, Schwartzberg LS, Jain RK, Pirolli M, Quach D, Quigley JM, Mu G, et al. Prevalence of hypercalcemia among cancer patients in the United States. Cancer Med. 2016;5(8):2091-2100.

15. Clines GA, Guise TA. Hypercalcaemia of malignancy and basic research on mechanisms responsible for osteolytic and osteoblastic metastasis to bone. Endocr Relat Cancer. 2005;12(3):549-583.

16. Mirrakhimov AE. Hypercalcemia of Malignancy: An Update on Pathogenesis and Management. N Am J Med Sci. 2015;7(11):483-493.

17. Ratcliffe WA, Hutchesson AC, Bundred NJ, Ratcliffe JG. Role of assays for parathyroid-hormone-related protein in investigation of hypercalcaemia. Lancet. 1992;339(8786):164-167.

18. Ikeda K, Ohno H, Hane M, Yokoi H, Okada M, Honma T, Yamada A, et al. Development of a sensitive two-site immunoradiometric assay for parathyroid hormone-related peptide: evidence for elevated levels in plasma from patients with adult T-cell leukemia/lymphoma and B-cell lymphoma. J Clin Endocrinol Metab. 1994;79(5):13221327.

19. Horwitz MJ, Tedesco MB, Sereika SM, Hollis BW, Garcia- 
Ocana A, Stewart AF. Direct comparison of sustained infusion of human parathyroid hormone-related protein-(1-36) [hPTHrP-(1-36)] versus hPTH-(1-34) on serum calcium, plasma 1,25-dihydroxyvitamin $\mathrm{D}$ concentrations, and fractional calcium excretion in healthy human volunteers. J Clin Endocrinol Metab. 2003;88(4):1603-1609.

20. Syed MA, Horwitz MJ, Tedesco MB, Garcia-Ocana A, Wisniewski SR, Stewart AF. Parathyroid hormone-related protein-(1-36) stimulates renal tubular calcium reabsorption in normal human volunteers: implications for the pathogenesis of humoral hypercalcemia of malignancy. J Clin Endocrinol Metab. 2001;86(4):1525-1531.

21. Horwitz MJ, Hodak SP, Stewart AF. Non-parathyroid hypercalcemia. In: Rosen CJ. Primer on the metabolic bone diseases and disorders of mineral metabolism. WileyBlackwell and The American Society for Bone and Mineral Research. 2013:562-571.

22. Minisola S, Pepe J, Piemonte S, Cipriani C. The diagnosis and management of hypercalcaemia. BMJ. 2015;350:h2723.

23. Deftos LJ, Burton DW, Baird SM, Terkeltaub RA. Hy- percalcemia and systemic lupus erythematosus. Arthritis Rheum. 1996;39(12):2066-2069.

24. Iida T, Satoh S, Kaneto H, Sasaki H, Naganawa Y, Ishigami K, Nakagaki S, et al. [A case of hypercalcemia associated with parathyroid hormone-related protein produced by the recurrence of B-cell lymphoma of the pancreas]. Nihon Shokakibyo Gakkai Zasshi. 2014;111(11):21632173.

25. Kapur S, Levin MB. Transformation of follicular lymphoma to double hit B-cell lymphoma causing hypercalcemia in a 69-year-old female: a case report and review of the literature. Case Rep Hematol. 2014;2014:619760.

26. Achten R, Verhoef G, Vanuytsel L, De Wolf-Peeters C. T-cell/histiocyte-rich large B-cell lymphoma: a distinct clinicopathologic entity. J Clin Oncol. 2002;20(5):12691277.

27. Aki H, Tuzuner N, Ongoren S, Baslar Z, Soysal T, Ferhanoglu B, Sahinler I, et al. T-cell-rich B-cell lymphoma: a clinicopathologic study of 21 cases and comparison with 43 cases of diffuse large B-cell lymphoma. Leuk Res. 2004;28(3):229-236. 